\title{
Management of asthma in adults
}

\author{
Meyer S. Balter MD, Alan D. Bell MD, Alan G. Kaplan MD, Harold Kim MD, R. Andrew Mclvor MD MSc
}

Previously published at www.cmaj.ca

\section{The case}

Sara is a 41-year-old secretary in an autobody shop who comes to see you for evaluation of intermittent episodes of wheezing and shortness of breath that have progressed over the past 2 years. She feels that she has more "colds" than her workplace colleague. Each episode lasts for 2-3 weeks, with persistent cough and dyspnea. She had wheezing and allergy symptoms in childhood, and her mother and 1 cousin have confirmed asthma. Over the past 6 months, she has noticed that because of her dyspnea, she is unable to keep up with her partner when they go salsa dancing. She is otherwise well and is taking no medications. She smokes a half package of cigarettes daily and has done so for 20 years.

When you first saw Sara a few weeks ago, you gave her a salbutamol inhaler; in addition, you arranged spirometry, both before and after administration of a bronchodilator. She reports that she has been using the salbutamol daily for dyspnea and when she wakens during the night with similar symptoms; the latter is still a weekly occurrence. Spirometry shows a mild obstructive defect, with forced expiratory volume in 1 second $\left(\mathrm{FEV}_{1}\right)$ of $2.29 \mathrm{~L}$ ( $78 \%$ of predicted), forced vital capacity of $3.48 \mathrm{~L}\left(99 \%\right.$ of predicted), a $\mathrm{FEV}_{1} / \mathrm{FVC}$ ratio of $66 \%$ and a $17 \%$ improvement in $\mathrm{FEV}_{1}$ after administration of an inhaled bronchodilator. You make a diagnosis of asthma. What is your proposed management?

A sthma remains the most common chronic disease of young adults, and the age-adjusted prevalence of this condition in Canada and other industrialized countries has continued to rise over the past 2 decades. ${ }^{1}$ Despite the increase in prevalence, asthma-related mortality in Canada has fallen steadily over the past 20 years; nonetheless, poor control of asthma symptoms continues to contribute to unnecessary morbidity, including unscheduled physician visits, days missed from work or school, limitation of daily activities and impairment of quality of life. ${ }^{3}$ Canadian guidelines for the diagnosis and treatment of asthma have existed since 1989 and were most recently updated in 2003. ${ }^{4}$ In this series, we are using case-based examples to highlight recent changes in recommendations for asthma management and to highlight practical aspects of diagnosis and treatment. The case used here focuses on the management of asthma in adults.

In this article, we discuss the following major changes in the management of asthma (since the 2003 update): the use of

\section{Key points}

- Low-dose inhaled corticosteroids are preferred as initial controller medication in the treatment of asthma.

- Leukotriene receptor antagonists should be prescribed for people with asthma who cannot or will not use inhaled corticosteroids.

- Long-acting $\beta_{2}$-agonists should be prescribed only as a component of single-inhaler combination therapy for asthma (i.e., in combination with inhaled corticosteroid).

- For asthma not controlled with low-dose inhaled corticosteroids, combination therapy with long-acting $\beta_{2^{-}}$ agonists and inhaled corticosteroids, in a single inhaler, is the preferred treatment choice.

- Patients with asthma should have regular follow-up visits, during which criteria for asthma control, compliance with medications and proper inhaler technique should be reviewed.

budesonide and formoterol in a single inhaler for both maintenance and reliever therapy; the earlier introduction of inhaled corticosteroid therapy in the treatment of mild asthma; the possible role of intermittent inhaled corticosteroid therapy for mild asthma; the importance of exploring the possibility of work-related asthma; and the role of obesity in asthma.

In addition, we re-emphasize the following important points about the diagnosis and treatment of asthma, as set out in previous guidelines: the importance of controlling contributing factors (e.g., environment, gastroesophageal reflux, sinus disease) in terms of achieving control, the primary role of inhaled corticosteroid monotherapy in the initial maintenance therapy of asthma, the importance of regular follow-up for asthma and attention to parameters of asthma control, and contraindications to regular monotherapy with long-acting $\beta_{2}$-agonists.

We employed a comprehensive approach, involving several search strategies, as described in detail in a previous article in this series, ${ }^{5}$ to identify studies published since the appearance of the 2003 Canadian asthma guidelines. ${ }^{4}$ We based our grades of evidence on those of the Canadian Task Force on Preventive Health Care, ${ }^{6}$ as described previously. ${ }^{5}$

From the Department of Medicine (Balter) and the Department of Family Practice (Kaplan), University of Toronto, Toronto, Ont.; the Department of Family Medicine (Bell), Humber River Regional Hospital, Toronto, Ont.; the Department of Medicine (Kim), University of Western Ontario, London, Ont.; Firestone Institute for Respiratory Health (Mclvor), St. Joseph's Healthcare, Hamilton, Ont.; and the Department of Medicine (Mclvor), McMaster University, Hamilton, Ont.

Cite as CMAJ 2009. DOI:10.1503/cmaj.080007 


\section{Initial management of untreated asthma}

Six main principles of asthma management are common for all patients: ${ }^{7}$ environmental control, regular anti-inflammatory therapy, appropriate use of inhalation therapy, consultation with a certified asthma educator, graduated approach to therapy (including "reliever" medication) and regular follow-up with the physician. These principles are illustrated in the asthma continuum (Figure 1) and explained in more detail below.

Environmental control and asthma education are critical but often neglected components of management. A thorough clinical history should be obtained, including details about the patient's home and work environments, with particular attention to known allergens, including pets, moulds and house dust mites (Table 1). Allergy testing should be considered. Smoking cessation and avoidance of second-hand smoke are also important.

Health care providers understand asthma as a chronic inflammatory disease provoking variable airflow obstruction and symptoms. Patients, however, often do not appropriately understand why the chronic nature of asthma makes adherence to maintenance anti-inflammatory therapy essential. The patient should be educated about the need for regular anti-inflammatory therapy, rather than sporadic relief of symptoms with bronchodilators.

Inhalation therapy is the cornerstone of asthma management, but many patients do not readily master the proper use of inhalers. All health care professionals should learn appropriate inhaler technique so that they can demonstrate these techniques to their patients and observe how patients perform them at all visits. Representative videos illustrating appropriate inhaler

\section{Adjust therapy to gain and maintain asthma control}

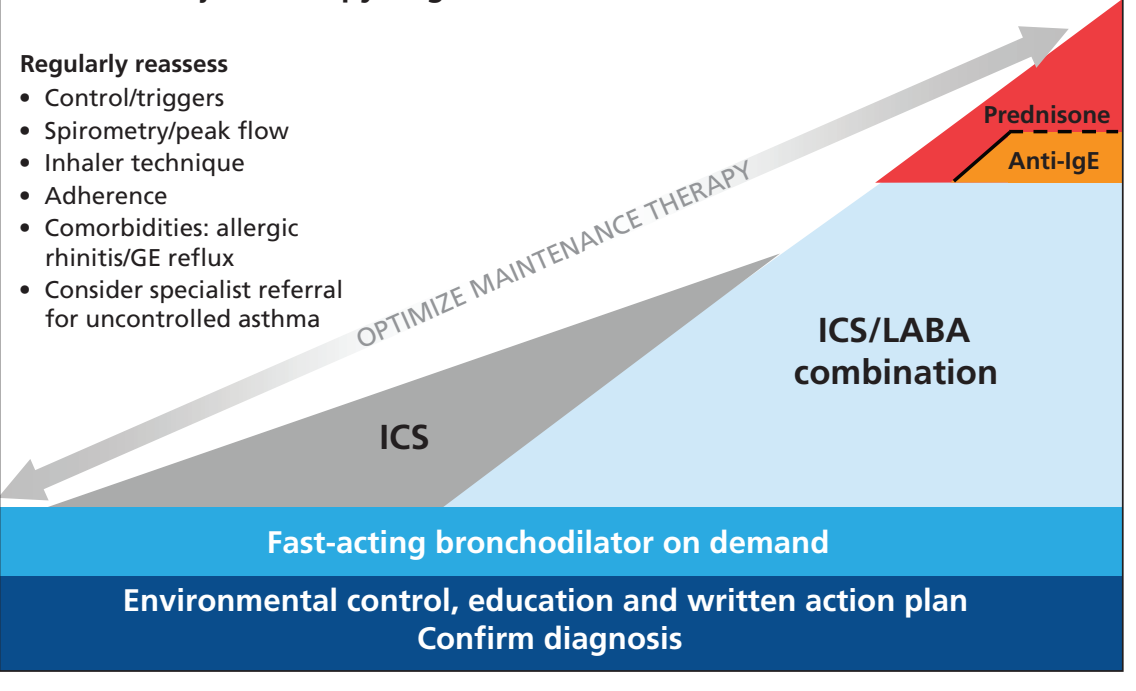

Figure 1: Continuum of asthma management for the continuum of increasing severity of asthma (from left to right). The vertical axis indicates treatment recommendations at each level of severity. The continuum illustrates the preferred strategies for escalation (from left to right) and de-escalation (from right to left) of long-term maintenance therapy, against a background of a patient-centred model of chronic disease management, consisting of regular follow-up and optimization of therapy adjusted according to assessments of control. The items in the list for regular reassessment (at left) apply to all patients with asthma and should be reviewed at each clinical encounter. Note: GE = gastroesophageal, ICS = inhaled corticosteroids, IgE = immunoglobulin E, LABA = longacting $\beta_{2}$-agonist. Copyright Canadian Thoracic Society, 2009. technique can be found at www.on.lung.ca/Health-Care Professionals/Provider-Education-Program/CD-ROMS.php.

Whenever possible, people with asthma should be referred to a certified asthma educator, a health care professional who has completed specialized training and passed a certification examination that covers methods of teaching asthma management, as well as aspects of learning and behavioural techniques. Such a service complements visits to the physician and ensures that patients receive consistent education about their disease. During these sessions, the educator reviews the patient's knowledge about asthma and provides a written action plan outlining how and when to adjust treatment. The educator prepares the plan, ch is based on control or worsening of the patient's asthma consultation with the primary care physician. If a certified che physician who is managing patient's asthma should prepare the written action plan.

graduated approach to therapy and illustrates the need for "reliever" medication (i.e., a rapid-acting $\beta_{2}$-agonist) for immediate relief of symptoms and "controller" medication (i.e., anti-inflammatory) for ongoing disease management. Every person with a diagnosis of asthma should be given a rapid-acting $\beta_{2}$-agonist for as-needed relief, and the large majority should be given an anti-inflammatory controller medication for regular use.

Long-term compliance with controller therapy is poor, because patients tend to stop therapy when their symptoms subside. Therefore, regular follow-up visits are important. At these visits, the physician should reassess asthma control, as well as any barriers to control, including lack of adherence with anti-inflammatory medication. Control should be assessed frequently, and the maintenance dose adjusted to the minimum required to maintain control. At each visit, compliance, inhaler technique, triggers, environment and comorbidities should be assessed.

\section{Environmental interventions}

Environmental exposures trigger symptoms and exacerbations of asthma. Previous asthma guidelines have recommended skin testing to common aeroallergens to help identify which allergen may be most relevant for a specific patient. ${ }^{4,8}$ Testing should be performed for the common indoor and outdoor aeroallergens that are pertinent to the patient's geographic region. These allergens may include house dust mite, cat, dog, cockroach, moulds and pollens. Reducing exposure to an allergen to which the patient is sensitized may improve asthma control and reduce the need for medication. ${ }^{8}$ However, allergenavoidance measures may be labourintensive, making adherence difficult and necessitating frequent reassessment and 
encouragement by treating physicians. Suggested questions for an indoor environmental history are listed in Table 1.

Most studies examining single-strategy interventions aimed at reducing exposure to single allergens have demonstrated no measurable benefits in asthma control. ${ }^{9}$ However, the concurrent use of several interventions individually tailored to known allergens has yielded significant benefit for children. ${ }^{10}$ Examples of such tailored interventions include use of allergenimpermeable covers for furniture and bedding, use of a vacuum cleaner equipped with a high-efficiency particulate air filter, use of a high-efficiency particulate air purifier in a child's bedroom if the child is exposed to second-hand smoke or is sensitized and exposed to cat or dog allergens or mould, and professional pest control for the homes of children sensitized and exposed to cockroach allergen. Although large randomized trials assessing interventions for multiple allergens in adults have not been performed, avoidance of identified allergens is usually recommended for adults with allergic asthma.

House dust mites are ubiquitous in humid environments. They are difficult to control and impossible to eliminate. Efforts to reduce mite allergens - including encasing mattresses, replacing carpet with hard-surface flooring, removing as many dust-gathering objects as possible and using high-efficiency particulate air filtration systems or chemicals - have been disappointing ${ }^{11}$ and should not be broadly recommended in isolation.

Although randomized controlled trials of avoidance of animal allergens have not been conducted, pets should be eliminated from the homes of people who have asthma and confirmed animal allergies. However, compliance with this recommendation is poor, and it may take many months for the allergen load to decline after an animal has been removed. ${ }^{12}$

Cockroach allergens are known triggers of asthma, ${ }^{13}$ and elimination may be valuable from the perspectives of both asthma control and general hygiene.

Moulds constitute a source of airborne allergens associated with worsening of asthma. Cleaning with fungicides, dehumidification to less than $50 \%$ humidity, high-efficiency particulate air filtration and central air conditioning may reduce the antigen load and severe symptoms of asthma in individuals with known fungal allergies. ${ }^{14}$

\section{Smoking and exposure to smoke}

Active smoking by patients with asthma is associated with worsening of symptoms and accelerated decline in lung function. ${ }^{15}$ Cigarette smoking may modify the inflammatory response in asthma and may be responsible for the decrease in response to inhaled corticosteroids that is typically observed among smokers. ${ }^{15}$ Exposure to environmental or second-hand smoke is associated with adverse outcomes in both children and adults with asthma. ${ }^{8,16}$

\section{Reliever medications}

Inhaled rapid-acting $\beta_{2}$-agonists act on the $\beta$-adrenergic receptors in the airways, leading to relaxation of the smooth muscles of the airway. These medications should be used to treat acute bronchoconstriction during exacerbations of asthma.
Table 1: Questions for indoor environmental history (level II evidence)

\begin{tabular}{ll}
\hline Question & \multicolumn{1}{c}{ Rationale } \\
\hline How old is your home? & $\begin{array}{l}\text { It is usually more difficult to control } \\
\text { humidity in older homes }\end{array}$ \\
$\begin{array}{l}\text { What type of heating is } \\
\text { used? }\end{array}$ & $\begin{array}{l}\text { Electric heating may be worse for } \\
\text { asthma }\end{array}$ \\
$\begin{array}{l}\text { Does the home have air } \\
\text { conditioning? }\end{array}$ & $\begin{array}{l}\text { Central air conditioning may improve } \\
\text { the ability to control the indoor } \\
\text { environment by keeping humidity }\end{array}$ \\
& $\begin{array}{l}\text { low and preventing outdoor } \\
\text { allergens from coming indoors }\end{array}$ \\
$\begin{array}{l}\text { Are there pets in the } \\
\text { home, particularly furry } \\
\text { mammals? }\end{array}$ & $\begin{array}{l}\text { Pets should be removed if patients } \\
\text { have a positive result on skin } \\
\text { testing }\end{array}$ \\
$\begin{array}{l}\text { What type of mattress } \\
\text { is used? }\end{array}$ & $\begin{array}{l}\text { Mattress should be encased if the } \\
\text { patient is allergic to house dust } \\
\text { mites; however, this measure is not } \\
\text { consistently effective }\end{array}$ \\
\hline $\begin{array}{l}\text { Is carpeting or other } \\
\text { upholstery present in } \\
\text { the bedroom? }\end{array}$ & $\begin{array}{l}\text { Remove if patient is allergic to dust } \\
\text { mites, although the benefits of } \\
\text { doing so have not been consistently } \\
\text { demonstrated }\end{array}$ \\
$\begin{array}{l}\text { Is there any obvious } \\
\text { mould by sight or smell? }\end{array}$ & $\begin{array}{l}\text { Clean with diluted bleach, and fix } \\
\text { any structural problems that might } \\
\text { lead to the mould }\end{array}$ \\
$\begin{array}{l}\text { Amoking cessation must be } \\
\text { smokers present? }\end{array}$ & $\begin{array}{l}\text { vigorously encouraged and } \\
\text { exposure to second-hand smoke } \\
\text { minimized }\end{array}$ \\
\hline
\end{tabular}

They may also be used before exercise to prevent symptoms of exertion-induced bronchoconstriction. ${ }^{17}$ Salbutamol and terbutaline have been available as reliever medications for many years. The long-acting $\beta_{2}$-agonist formoterol is unique in that it also has a rapid onset of action and can therefore be used to relieve acute symptoms. However, regular use of longacting $\beta_{2}$-agonists as monotherapy has been associated with increased morbidity and mortality and should be avoided. ${ }^{18-20}$

\section{Initial controller medications}

\section{Inhaled corticosteroids}

Inhaled corticosteroids (Table 2) ${ }^{8}$ are the most effective maintenance treatment for asthma and represent the standard of care. ${ }^{7}$ Regular use of inhaled corticosteroids decreases symptoms and exacerbations and improves the results of spirometry and the patient's quality of life.

Low-dose inhaled corticosteroid monotherapy is recommended as first-line maintenance therapy for most patients with asthma. ${ }^{4,7}$ The addition of long-acting $\beta_{2}$-agonists has not improved clinical outcomes for patients whose asthma is well controlled with low-dose inhaled corticosteroids, ${ }^{21,22}$ and, for most patients with asthma, there is no indication for using combination therapy as initial maintenance therapy.

Low- or moderate-dose inhaled corticosteroid therapy is generally free of serious adverse effects but may cause local or systemic adverse effects. Local adverse effects include oral thrush 
Table 2: Dose equivalences for inhaled corticosteroids

\begin{tabular}{lccc}
\hline & & Dose level; daily dose, $\mu \mathrm{g}$ \\
\cline { 2 - 4 } Drug name & Low & Medium & High \\
\hline Beclomethasone dipropionate (chlorofluorocarbon; CFC)* & $200-500$ & $>500-1000$ & $>1000-2000$ \\
Beclomethasone dipropionate (hydrofluoralkane; HFA)* & $100-250$ & $>250-500$ & $>500-1000$ \\
Budesonide & $200-400$ & $>400-800$ & $>800-1600$ \\
Ciclesonide & $100-200$ & $>200-400$ & $>400-1600$ \\
Fluticasone & $100-250$ & $>250-500$ & $>500-1000$ \\
\hline
\end{tabular}

*Dose equivalences for CFC and HFA propellants differ because of differences in particle size and resulting differences in airway deposition.

and dysphonia. The incidence of oral thrush with the use of inhaled corticosteroids depends on the particular drug, the dose and the delivery system. Rates in controlled trials ranged from $0 \%$ to $5 \%$ and appeared highest with fluticasone, ${ }^{23}$ but the methods used (visual scores alone v. culture) have varied substantially among trials, which makes it difficult to compare medications. The risk of oral candidiasis may be greatly reduced by rinsing and spitting after inhaling the medication or by using a valved holding chamber. The incidence of dysphonia has ranged from $2 \%$ to $6 \%$ in clinical trials. This adverse effect is dosedependent and may be related to reversible myopathy of the vocal cords. Both of these local adverse effects may occur less frequently with the pro-drug ciclesonide because most of the conversion to the active compound, desisobutyryl-ciclesonide, occurs in the lung. ${ }^{24}$ Systemic adverse effects are uncommon and include adrenal suppression, changes in bone density, cataracts, glaucoma and growth retardation. ${ }^{25,26}$ Because of the very low systemic exposure to steroids, these adverse events are rare, occurring in less than $1 \%$ of users. Bruising is slightly more common, particularly in older patients and those using higher doses. Valved holding chambers may reduce systemic adverse effects as well, but not those caused by absorption of the drugs after delivery to the lungs.

\section{Leukotriene receptor antagonists}

The leukotriene receptor antagonists are a class of nonsteroidal anti-inflammatory asthma medications that are safe and well tolerated. Drugs from this class that are available in Canada include montelukast and zafirlukast. These medications act by specifically blocking the cysteinyl leukotriene receptor-1 receptors. When taken regularly they can be effective in the treatment of asthma. ${ }^{27}$ However, they are less effective than inhaled corticosteroids; therefore, if they are used as monotherapy, they should be reserved for patients who cannot or will not take inhaled corticosteroids and for those in whom inhaled corticosteroids have had no benefit. ${ }^{4,28}$

\section{The case continued}

The course of treatment for Sara is now clear, given the diagnosis and the available treatment options. You should take the following steps:

- Discuss smoking cessation with Sara and offer referral to a smoking cessation clinic. Consider prescribing smoking cessation aids, such as nicotine replacement, bupropion or varenicline.

- Counsel Sara about her disease, or refer her to a certified asthma educator at a local asthma centre, if available.

- Offer Sara both verbal and written asthma education, including a written action plan (for an example, see Appendix 1, at www.cmaj.ca/cgi/content/full/cmaj.080007/DC1); this may be performed by the asthma educator, if available.

- Prescribe a low dose of an inhaled corticosteroid (beclamethasone dipropionate $100 \mu \mathrm{g}$ one inhalation twice daily, budesonide $200 \mu \mathrm{g}$ one inhalation twice daily, ciclesonide $200 \mu \mathrm{g}$ one inhalation every morning or fluticasone $125 \mu \mathrm{g}$ one inhalation twice daily), along with a rapid-acting $\beta_{2}$-agonist for use as a rescue medication.

- Arrange a follow-up visit with Sara in 4 to 6 weeks to assess her asthma control (Box 1), to review her inhaler technique and to determine the clinical response.

When Sara returns 6 weeks later, she tells you that she "feels fine." However, she reports that salsa dancing still leaves her winded and precipitates coughing. About once a week, she wakes up at 3 am feeling short of breath but feels better after taking a puff of salbutamol.

\section{Is Sara's asthma under acceptable control?}

The most important part of any follow-up visit with a patient who has asthma is to review control of the disease by specifically asking the questions listed in Box 1 as a list. According to these criteria, the fact that Sara is still experiencing exercise limitations and weekly nocturnal awakenings (i.e., missing 2 criteria) indicates that her asthma remains uncontrolled. Uncontrolled asthma is associated with a greater frequency of adverse outcomes than is well-controlled asthma, including exacerbations requiring visits to the emergency department and admission to hospital. ${ }^{29}$

\section{Treating uncontrolled asthma}

For a patient whose asthma is inadequately controlled, the physician must use a series of specific questions to determine the cause:

1. Is the diagnosis correct?

Confirm the diagnosis with spirometry testing before and after administration of a bronchodilator if this has not previ- 
ously been done. In Sara's case, this testing was done at the time of her diagnosis.

\section{Is the patient taking his or her medications?}

Nonadherence to prescribed inhaled medications is common among patients with asthma, as it is for patients with many chronic lung diseases. Sara says that she has missed only the occasional dose of inhaled corticosteroid and shows you her inhaler device. You see that she has already refilled the initial prescription, given 6 weeks ago. This suggests that she is using the medication.

\section{Is the patient's inhaler technique adequate?}

Sara saw an asthma educator when asthma was originally diagnosed. At that time, the educator explained the pathogenesis of the disease and the need for long-term anti-inflammatory therapy. In addition, the asthma educator reviewed proper inhaler technique and chose an appropriate delivery device for Sara. A review of her technique in the office reveals that she is using her current device well.

4. Is the patient exposed to allergens, irritants or occupational sensitizers?

Sara confirms that she has not smoked since her last visit to you but admits that she is anxious and still craves cigarettes. Cigarette smoking leads to poor asthma control and an accelerated loss of lung function, and impairs the effectiveness of inhaled corticosteroid therapy. ${ }^{15}$ Smoking cessation is essential if good control of asthma is to be achieved.

Work-related asthma is frequent among adults with asthma. ${ }^{30}$ Work-related asthma encompasses occupational asthma, which is caused by a specific work exposure (caused by sensitization, an immunologic response or exposure to a high-level irritant at work), and work-exacerbated asthma, which has non-work-related causes but is worsened by exposures at work. Common work settings associated with occupational asthma include health care, work with diisocyanates (e.g., production of polyurethane foam or use of spray paints) and work with animals, food or wood. Both occupational asthma and work-exacerbated asthma should be carefully investigated, starting with a detailed history (Box 2), ${ }^{31}$ although the historical features listed in Box 2 are not specific for occupational asthma. ${ }^{32}$

Detailed investigations usually require referral to a specialist and should be initiated early, while the patient is still working. A diagnosis of work-related asthma may have sub-

Box 1: Criteria for assessing control of asthma (level III evidence) ${ }^{4}$

- Daytime symptoms fewer than 4 days per week

- Nighttime symptoms fewer than 1 night per week

- Normal physical activity

- No exacerbations

- No absenteeism because of asthma

- Fewer than 4 doses per week of a fast-acting $\beta_{2}$-agonist bronchodilator

- Forced expiratory volume in 1 second or peak flow at least $90 \%$ of personal best

- Diurnal variability in peak flow less than $10 \%-15 \%$ stantial occupational and psychosocial implications, and the patient should not be advised to leave work until a diagnosis has been confirmed as far as possible by a specialist. If the patient has work-related asthma, some modifications may be required to reduce exposure at work, and a change in workplace may occasionally be required.

Sara has told you that she works in an autobody shop, a setting where sprays containing diisocyanate are frequently used, but her work is in a well-ventilated area where she is not exposed to dust or fumes. She has not noticed her symptoms worsening during the course of the work week.

5. Does the patient have ongoing nasal symptoms?

The upper and lower airways form a continuum, such that anything that inflames the upper airways will worsen control of asthma. Sara has noted nasal stuffiness in the past, which she attributed to renovations in her apartment complex a few years ago, but she denies any sinus pain or a sensation of postnasal drip or nasal stuffiness at the present time.

6. Does the patient have gastresophageal reflux disease?

The association between gastresophageal reflux disease and asthma is well established, ${ }^{33}$ although the evidence that treating reflux improves asthma control is still equivocal. ${ }^{34}$ Treating reflux seems to improve certain symptoms of asthma, particularly a cough that is bothersome for the patient, but it does not usually lead to an improvement in the results of spirometry.

7. Is the patient taking a medicine that could worsen asthma? About $10 \%$ of people with asthma will experience worsening of symptoms with nonsteroidal anti-inflammatory drugs. ${ }^{35}$ There may also be some worsening with $\beta$-blockers, although

\section{Box 2: History of work-related asthma (level III evidence)}

For patients with asthma:

- Suspect work-related factors

- Document the occupational history:

- Patient's job and exposures at work

- Date when asthma started or worsened

- For symptoms of cough, wheeze, chest tightness or shortness of breath:

- Are symptoms worse with work exposures?

- Are symptoms worse when working (e.g., at work, after work if symptoms are delayed)?

- Are symptoms better when away from work (e.g., weekends or holidays)?

For patients with adult-onset asthma:

- Did asthma begin with a work incident?

For patients with asthma who answered "yes" to any question about symptoms or whose asthma began with a work incident or both:

- Obtain additional details about work exposures, temporal work-related associations with symptoms, and the presence of associated nasal, eye and skin symptoms, as well as frequency of symptoms

- Obtain details about the use and type of any respiratory protective devices that the patient uses at work

- Ask the patient if any coworkers have similar symptoms at work 
this is less likely with the newer $\beta_{1}$-specific agents (e.g., atenolol, bisoprolol, metoprolol). ${ }^{36}$

8. Is the patient obese?

Obesity is associated with an increased risk of asthma, particularly among women.$^{37}$ Preliminary evidence suggests that weight loss improves some outcomes of asthma. ${ }^{38}$ Sara has a body mass index of 23, so no further discussion of diet or weight loss is entertained.

9. Does the patient have a serious complication of asthma? Severe consequences of asthma such as allergic bronchopulmonary aspergillosis and Churg-Strauss vasculitis are rare; they will be discussed in a subsequent article in this series.

Now that you have considered and addressed all other causes of poor asthma control in this case, you decide to augment Sara's therapy.

\section{Optimizing therapy}

\section{Is it better to increase the dose of inhaled corticosteroids or to add another class of medication?}

Inhaled corticosteroids have a relatively flat dose-response curve. Although some patients benefit from higher doses of inhaled corticosteroids, there are no readily available clinical tools to identify such patients in advance. Therefore, if asthma is not controlled (Box 1) in a patient who is adherent with therapy (dose equivalent to fluticasone $250 \mu \mathrm{g} / \mathrm{day}$ ), it is recommended to add another class of medication, usually a long-acting $\beta_{2}$-agonist, rather than increasing the dose of inhaled corticosteroid. It is important to reiterate that adherence to inhaled corticosteroids is often poor; therefore, before prescribing an additional drug, the treating clinician must reassess adherence to the prescribed dosage of inhaled corticosteroid and, if necessary, counsel the patient regarding barriers to and improvement of adherence.

\section{Which is the best therapy to add to inhaled corticosteroids?}

Adding a long-acting $\beta_{2}$-agonist to low-dose inhaled corticosteroids leads to fewer exacerbations, a decreased need for reliever medication, fewer nocturnal symptoms and improved quality of life, relative to doubling the dose of inhaled corticosteroid. ${ }^{19,39}$ Similarly, adding a leukotriene receptor antagonist to inhaled corticosteroids yields better results than the use of either agent alone..$^{40,41}$ The main question is which medication to add. Most studies favour the combination of inhaled corticosteroid and long-acting $\beta_{2}$-agonist because of greater improvements in lung function ${ }^{42}$ and a higher response rate than occurs with the addition of leukotriene or a further increase in the dose of inhaled corticosteroid. Also, these 2 drugs can be combined in the same delivery device, which may improve adherence and decrease the likelihood that the patient will stop using the inhaled corticosteroid, thereby guarding against the potential risks of long-acting $\beta_{2}$-agonist monotherapy. Inhaled corticosteroids remain the most important component of asthma controller therapy.

Some patients may respond better to a leukotriene receptor antagonist than to a long-acting $\beta_{2}$-agonist. This is not readily predictable but such patients may include those with significant inflammation of the upper airways, as occurs with allergic rhinitis or nasal polyposis, ${ }^{43}$ those with sensitivity to acetylsalicylic acid ${ }^{44}$ and perhaps those with significant exercise-induced bronchoconstriction. ${ }^{45}$ However, these responses are not consistent, and a trial of one medication, followed by a trial of the other if the first one fails, is a common approach.

Another option for add-on therapy is theophylline. This drug has been available for decades, but because of its narrow therapeutic window and frequent adverse effects, it is not commonly prescribed and should be reserved for patients in whom long-acting $\beta_{2}$-agonist and leukotriene receptor antagonist therapy has failed. ${ }^{4.8}$ The role of newer therapies such as anti-immunoglobulin $\mathrm{E}$ will be covered in a subsequent article in this series.

\section{Outcome of the case}

After satisfying yourself that Sara is using her inhaler properly, you decide to start her on an inhaler that combines an inhaled corticosteroid and a long-acting $\beta_{2}$-agonist. There are 2 possible ways to use such therapy.

The first option, known as fixed therapy, has patients taking a set dose of medications on a regular basis and taking extra doses of fast-acting bronchodilators (e.g., salbutamol, formoterol) or higher doses of inhaled corticosteroid if their symptoms worsen. This can be accomplished with either of the combination inhalers available in Canada, fluticasone-salmeterol or budesonide-formoterol.

With the second option, a single inhaler is used for both maintenance and relief; only the budesonide-formoterol combination is suitable for this approach. In addition to the baseline maintenance dose of budesonide-formoterol, patients may use additional doses as a reliever medication over the course of the day to reduce the severity of acute symptoms and to reduce the frequency and severity of exacerbations. ${ }^{46,47}$ This approach takes advantage of formoterol's rapid onset, as well as the sustained activity and safety of the drug combination at higher doses. It is important to point out that this is not asneeded therapy for asthma, but rather as-needed addition of therapy to a stable maintenance dose of combination therapy.

Both fixed dosing and single-inhaler therapy for maintenance and relief of asthma lead to excellent outcomes for the patient if taken as prescribed. However, there is currently no way to predict which approach will work best in an individual patient. Compliance with prescribed therapy is likely to be higher if the patient is a partner in choosing which approach is taken and if appropriate use of the regimen is reinforced by a certified asthma educator.

Whenever the patient's asthma therapy is changed, a follow-up visit within 1-3 months should be scheduled. At that follow-up visit, the clinician should assure compliance and proper inhalation technique, assess parameters of asthma control, review possible triggers for worsening of symptoms and review the components of the written action plan. In addition, once control of asthma has been achieved, the physician and patient may contemplate slowly reducing, but not stopping, maintenance therapy. 


\section{Gaps in knowledge and future directions}

The key messages for the management of asthma in adults are presented in Box 3.

Clinical parameters and lung function alone cannot be used to determine which patients require higher doses of inhaled corticosteroids, either for maintenance therapy (as opposed to adding another class of medication) or for treatment of exacerbations. Distinguishing eosinophilic inflammation of the airways, which is typically found in asthma, from non-eosinophilic inflamma-

Box 3: Key messages for the management of asthma in adults

- Cigarette smoking leads to progressive impairment of lung function and reduces the efficacy of inhaled corticosteroids, the primary pharmacologic therapy for asthma. Smoking cessation should be strongly encouraged and facilitated for all patients with asthma (grade A recommendation; level II-1 evidence).

- Indoor and outdoor allergens contribute to the severity of asthma symptoms and the frequency of exacerbations, and attempts to reduce exposure to allergens should be encouraged (grade D recommendation; level I evidence).

- The possibility of occupational or workplace-related asthma should be explored by obtaining an appropriate history. Prevention of further exposure in an occupationally sensitized individual is important in the management of asthma (grade A recommendation; level II evidence).

- Anyone with a diagnosis of asthma should be educated about the nature of the disease, the role of medications and the use of inhaler devices and should be given a personalized, written action plan. These are key steps in empowering the patient to assist in the management of the disease (grade A recommendation; level I evidence).

- All persons with asthma should be given a fast-acting bronchodilator for relief of symptoms (grade A recommendation; level I evidence).

- Low-dose inhaled corticosteroids should be introduced as the initial controller medication for the treatment of asthma (grade A recommendation; level I evidence).

- People with asthma who cannot or will not use inhaled corticosteroids should be given alternative antiinflammatory therapy in the form of a leukotriene receptor antagonist (grade A recommendation; level I evidence).

- Long-acting $\beta_{2}$-agonists should not be used as monotherapy for asthma (grade E recommendation; level II-3 evidence).

- In patients with asthma that is not controlled with lowdose inhaled corticosteroids, combination inhalers with a long-acting $\beta_{2}$-agonist and an inhaled corticosteroid are superior to high-dose inhaled corticosteroids or a combination of inhaled corticosteroid and leukotriene receptor antagonist (grade A recommendation; level I evidence).

- Combination therapy with budesonide and formoterol in a single inhaler can be used as both maintenance and relief therapy to improve the parameters of asthma control and to reduce the frequency of exacerbations (grade A recommendation; level I evidence). This approach has not been studied, and cannot be recommended, with other combination products.

- Patients with asthma should have regular follow-up visits, during which criteria for control of their disease, compliance with medications and proper inhaler technique, triggers for worsening and the written action plan should be reviewed (grade B recommendation; level II-2 evidence). tion, which is typical of infectious and other conditions, may help physicians to better diagnose asthma and to treat exacerbations appropriately. Sputum cytology and determination of exhaled nitric oxide levels and possibly exhaled carbon monoxide levels are promising noninvasive tests that may help to guide therapy. ${ }^{48-51}$ Use of these tests is currently limited to research institutions, and they are not funded for general use. Further research is required to prospectively define the role of these emerging tests in optimizing the diagnosis and management of asthma.

Several genes have been identified that predict susceptibility to asthma. These genes may operate by causing elevated production of immunoglobulin E, airway hyper-responsiveness or atopy through other mechanisms. ${ }^{52-54}$ Other loci have been identified that may predict response to $\beta_{2}$-agonists, ${ }^{55}$ inhaled corticosteroids ${ }^{56}$ and leukotriene antagonists. ${ }^{57}$ The use of pharmacogenomics to predict which patients might respond best to a particular medication is the goal of current research but is probably years away from clinical utility.

There has been recent interest in the use of "as-needed" maintenance therapy for asthma. This involves patients not taking any anti-inflammatory agent on a regular basis but using an anti-inflammatory agent either alone or in combination with a bronchodilator when they have symptoms. Although some interesting and positive preliminary results have been obtained with this approach, ${ }^{58,59}$ the studies so far have all been conducted in patients with mild persistent asthma. One study found similar improvement in peak flow with intermittent and daily use of inhaled corticosteroids in mild asthma, but superior suppression of inflammatory markers with regular use of inhaled corticosteroids. ${ }^{58}$ Other important clinical end points, including exacerbations, were not examined. ${ }^{58}$ The patient in this case, Sara, has more severe symptoms; as such, current evidence would not support considering her as a candidate for intermittent therapy.

\section{This article has been peer reviewed.}

Competing interests: Meyer Balter serves on advisory boards for AstraZeneca, Boehringer Ingelheim, GlaxoSmithKline, Merck Frosst, Nycomed and Pfizer and has received speaker fees from each of these companies over the past 2 years. Alan Bell has been a member of AstraZeneca Canada's National Advisory Board for Respiratory Medicine from 2003 to the present and has received travel reimbursement to attend meetings of this board. He has also received consulting contracts and speaker fees from this board. He has received compensation for conducting clinical trials in respiratory disease from the following companies: AstraZeneca Canada, Nycomed Canada and Boehringer Ingelheim Canada. Alan Kaplan has received honoraria for talks from AstraZeneca, GlaxoSmithKline, Nycomed, Boehringer Ingelheim and Pfizer. He has served on advisory boards for Merck Frosst, Nycomed, AstraZeneca and Boehringer Ingelheim. He has received travel reimbursement to meetings of the European Respiratory Society from Merck and AstraZeneca. Harold Kim has received speaker fees and has served on advisory boards for Merck, GlaxoSmithKline, AstraZeneca, Graceway and Nycomed. Andrew McIvor has attended advisory board meetings and provided continuing medical education for which he has received honoraria from pharmaceutical companies involved in asthma management: AstraZeneca, Boehringer Ingelheim, Graceway, GlaxoSmithKline, Novartis, Merck Frosst and Pfizer.

Contributors: All authors contributed to the development and editing of the publication, and all approved the version submitted for publication.

Funding: The Canadian Thoracic Society has received funding to facilitate the knowledge translation activities of the CTS Asthma Committee from AstraZeneca Canada, GlaxoSmithKline Inc., Merck Frosst Canada and Novartis Pharmaceuticals. None of the sponsors played a role in the collection, review, analysis or interpretation of the scientific literature or in any decisions regarding the key messages presented in the case studies. 


\section{REFERENCES}

1. Canadian Institute for Health Information. Respiratory disease in Canada. Ottawa (ON): The Institute; 2001. p. 45-55.

2. It's your health: asthma. Ottawa (ON): Health Canada; 2006. Available: www.hcsc.gc.ca/hl-vs/iyh-vsv/diseases-maladies/asthm-eng.php (accessed 2009 Jul. 17).

3. Fitzgerald JM, Boulet JP, McIvor RA, et al. Asthma control in Canada remains suboptimal: The Reality of Asthma Control (TRAC) study. Can Respir J 2006;13:253-9.

4. Lemiere C, Bai T, Balter M, et al.; Canadian Adult Consensus Group of the Canadian Thoracic Society. Adult asthma consensus guidelines update 2003. Can Respir J 2004;11(Suppl A):9A-18A

5. Kaplan A, Balter M, Bell A, Kim H, McIvor RA. Diagnosis of asthma in adults CMAJ 2009. DOI:10.1503/cmaj.080006.

6. Canadian Task Force on Preventive Health Care. New grades for recommendation from the Canadian Task Force on Preventive Health Care. CMAJ 2003;169:207-8.

7. Becker A, Lemiere C, Berube D, et al. Summary of recommendations from the Canadian Asthma Consensus guidelines, 2003. CMAJ 2005;173(6 Suppl):S3-11.

8. Global strategy for asthma management and prevention. Global Initiative for Asthma; 2007. Available: www.ginasthma.com/Guidelineitem.asp?11=2\&12 =1\&intId=60 (accessed 2009 Aug. 31).

9. Custovic A, Simpson A, Chapman MD, et al. Allergen avoidance in the treatment of asthma and atopic disorders. Thorax 1998;53:63-72.

10. Morgan WJ, Crain EF, Gruchalla RS, et al. Results of a home-based environmental intervention among urban children with asthma. N Engl J Med 2004:351:1068-80.

11. Gotzsche PC, Johansen HK. House dust mite control measures for asthma Cochrane Database Syst Rev 2008;(2):CD001187.

12. Wood RA, Chapman MD, Adkinson NF Jr, et al. The effect of cat removal on allergen content in household-dust samples. J Allergy Clin Immunol 1989;83:730-4.

13. Custovic A, Green R, Taggart SC, et al. Domestic allergens in public places. II: Dog (Can f1) and cockroach (Bla g 2) allergens in dust and mite, cat, dog and cockroach allergens in the air in public buildings. Clin Exp Allergy 1996;26:1246-52.

14. Denning DW, O'Driscoll BR, Hogaboam CM, et al. The link between fungi and severe asthma: a summary of the evidence. Eur Respir J 2006;27:615-26.

15. Tomlinson JEM, McMahon AD, Chaudhuri R, et al. Efficacy of low and high dose inhaled corticosteroid in smokers versus non-smokers with mild asthma. Thorax 2005;60:282-7.

16. Eisner MD, Klein J, Hammond SK, et al. Directly measured second hand smoke exposure and asthma health outcomes. Thorax 2005;60:814-21.

17. Godfrey S, Bar-Yishay E. Exercise-induced asthma revisited. Respir Med 1993;87:331-44

18. Spitzer WO, Suissa S, Ernst P, et al. The use of beta-agonists and the risk of death and near death from asthma. N Engl J Med 1992;326:501-6.

19. Ernst P, McIvor A, Ducharme FM, et al. Safety and effectiveness of long-acting inhaled beta-agonist bronchodilators when taken with inhaled corticosteroids. Ann Intern Med 2006;145:692-4.

20. O'Byrne PM, Adelroth E. Beta2 deja vu. Chest 2006;129:3-5.

21. O'Byrne PM, Barnes PJ, Rodriguez-Roisin R, et al. Low dose inhaled budesonide and formoterol in mild persistent asthma: the OPTIMA randomized trial. Am J Respir Crit Care Med 2001;164:1392-7.

22. O'Byrne P M. How much is too much? The treatment of mild asthma. Eur Respir J 2007;30:403-6.

23. Rachelefsky GS, Liao Y, Faruqi R. Impact of inhaled corticosteroid-induced oropharyngeal adverse events: results from a meta-analysis. Ann Allergy Asthma Immunol 2007;98:225-38.

24. Nave R, Zech K, Bethke TD. Lower oropharyngeal deposition of inhaled ciclesonide via hydrofluoroalkane metered-dose inhaler compared with budesonide via chlorofluorocarbon metered-dose inhaler in healthy subjects. Eur J Clin Pharmacol 2005;61:203-8.

25. Tattersfield AE, Harrison TW, Hubbard RB, et al. Safety of inhaled corticosteroids. Proc Am Thorac Soc 2004;1:171-5.

26. Lipworth BJ. Systemic adverse effects of inhaled corticosteroid therapy: a systematic review and meta-analysis. Arch Intern Med 1999;159:941-55.

27. Lipworth BJ. Leukotriene-receptor antagonists. Lancet 1999;353:57-62.

28. Ducharme FM. Inhaled corticosteroids versus leukotriene antagonists as first-line therapy for asthma: a systematic review of current evidence. Treat Respir Med 2004:3:399-405

29. Chapman KR, Boulet LP, Rea RM, et al. Suboptimal asthma control: prevalence, detection and consequences in general practice. Eur Respir J 2008;31:320-5.

30. Blanc PD, Toren K. How much asthma can be attributed to occupational factors Am J Med 1999;107:580-7.

31. Tarlo SM, Balmes J, Balkissoon R, et al. Diagnosis and management of workrelated asthma: American College of Chest Physicians Consensus Statement. Chest 2008;134(3 Suppl):1S-41S

32. Beach J, Russell K, Bliss S, et al. A systematic review of the diagnosis of occupational asthma. Chest 2007;131:569-78.

33. Harding SM. Gastroesophageal reflux: a potential asthma trigger. Immunol Allergy Clin North Am 2005;25:131-48.

34. Leggett JJ, Johnston BT, Mills M, et al. Prevalence of gastroesophageal reflux in difficult asthma: relationship to asthma outcome. Chest 2005;127:1227-31.

35. Kowalski ML. Asprin-sensitive rhinosinusitis and asthma. Clin Allergy Immunol 2007; $19: 147-75$

36. Salpeter S, Ormiston T, Salpeter E. Cardioselective beta-blockers for reversible airway disease. Cochrane Database Syst Rev 2002;(4):CD002992.

37. Beuther DA, Sutherland ER. Overweight, obesity, and incident asthma: a meta-analysis of prospective epidemiologic studies. Am J Respir Crit Care Med 2007;175:661-6.
38. Eneli IU, Skybo T, Camargo CA Jr. Weight loss and asthma: a systematic review. Thorax 2008;63:671-6.

39. Shrewsbury S, Pyke S, Britton M. Meta-analysis of increased doses of inhaled steroid or addition of salmeterol in symptomatic asthma (MIASMA). BMJ 2000;320:1368-73.

40. Laviolette M, Malmstrom K, Lu S, et al. Montelukast added to inhaled beclomethasone in treatment of asthma. Montelukast/Beclomethasone Additivity Group. Am J Respir Crit Care Med 1999;160:1862-8.

41. Price DB, Hernandez D, Magyar P, et al. Randomised controlled trial of montelukast plus inhaled budesonide versus double dose inhaled budesonide on control in mild to moderate asthma. Thorax 2003;58:211-6.

42. Ducharme FM, Lasserson TJ, Cates CJ. Long-acting beta2-agonists versus antileukotrienes as add-on therapy to inhaled corticosteroids for chronic asthma Cochrane Database Syst Rev 2006;(4):CD003137.

43. Nayak A, Langdon RB. Montelukast in the treatment of allergic rhinitis: an evidence-based review. Drugs 2007;67:887-901.

44. Berges-Gimeno MP, Simon RA, Stevenson DD. The effect of leukotriene-modifier drugs on aspirin-induced asthma and rhinitis reactions. Clin Exp Allergy 2002;32:1491-6.

45. Philip G, Pearlman DS, Villeran C, et al. Single-dose montelukast or salmeterol as protection against exercise-induced bronchoconstriction. Chest 2007;132:875-83.

46. Rabe KF, Atienza T, Magyar P, et al. Effect of budesonide in combination with formoterol for reliever therapy in asthma exacerbations: a randomised, doubleblind study. Lancet 2006;368:744-53.

47. Pedersen S. Budesonide plus formoterol for reliever therapy in asthma. Lancet 2006;368:707-8

48. Smith AD, Cowan JO, Brassett KP, et al. Use of exhaled nitric oxide measurements to guide treatment in chronic asthma. $N$ Engl J Med 2005;352:2163-73.

49. Green RH, Brightling CE, McKenna S, et al. Asthma exacerbations and sputum eosinophil counts: a randomised controlled trial. Lancet 2002;360:1715-21.

50. Pizzichini MM, Popov TA, Efthimiadis A, et al. Spontaneous and induced sputum to measure indices of airway inflammation in asthma. Am J Respir Crit Care Med 1996;154:866-9.

51. Taylor DR, Pijnenburg MW, Smith AD, et al. Exhaled nitric oxide measurements: clinical application and interpretation. Thorax 2006;61:817-27.

52. Holloway JW, Beghe B, Holgate ST. The genetic basis of atopic asthma. Clin Exp Allergy 1999;29:1023-32.

53. Wiesch DG, Meyers DA, Bleecker ER. Genetics of asthma. J Allergy Clin Immunol 1999;104:895-901.

54. Ober C. Perspectives on the past decade of asthma genetics. J Allergy Clin Immunol 2005;116:274-8.

55. Israel E, Chinchilli VM, Ford JG, et al. Use of regularly scheduled albuterol treatment in asthma: genotype-stratified, randomised, placebo-controlled cross-over trial. Lancet 2004;364:1505-12.

56. Ito K, Chung KF, Adcock IM. Update on glucocorticoid action and resistance. $J$ Allergy Clin Immunol 2006;117:522-43.

57. In $\mathrm{KH}$, Asano $\mathrm{K}$, Beier D, et al. Naturally occurring mutations in the human 5 lipoxygenase gene promoter that modify transcription factor binding and reporter gene transcription. J Clin Invest 1997;99:1130-7.

58. Boushey HA, Sorkness CA, King TS, et al. Daily versus as-needed corticosteroids for mild persistent asthma. N Engl J Med 2005;352:1519-28.

59. Papi A, Canonica GW, Maestrelli P, et al. Rescue use of beclomethasone and albuterol in a single inhaler for mild asthma. N Engl J Med 2007:356:2040-52.

Correspondence to: Dr. Meyer Balter, Mount Sinai Hospital, 600 University Ave., Suite 6-207, Toronto ON M5G 1X5; fax416 586-4736; mbalter@mtsinai.on.ca

\section{Articles to date in this series}

- Subbarao P, Mandhane PJ, Sears MR. Asthma: epidemiology, etiology and risk factors. CMA 2009. DOI:10.1503/cmaj.080612.

- Kaplan AG, Balter MS, Bell AD, et al. Diagnosis of asthma in adults. CMAJ 2009. DOI:10.1503/cmaj.080006.

This article is the third in a 7-part case study series that was developed as a knowledge translation initiative of the Canadian Thoracic Society Asthma Committee. The series aims to educate and inform primary care providers and nonrespiratory specialists about the diagnosis and management of asthma. The key messages presented in the cases are not clinical practice guidelines but are based on a review of the most recent scientific evidence available. Financial support for the publication of this series has been provided, in part, by the Canadian Thoracic Society. 

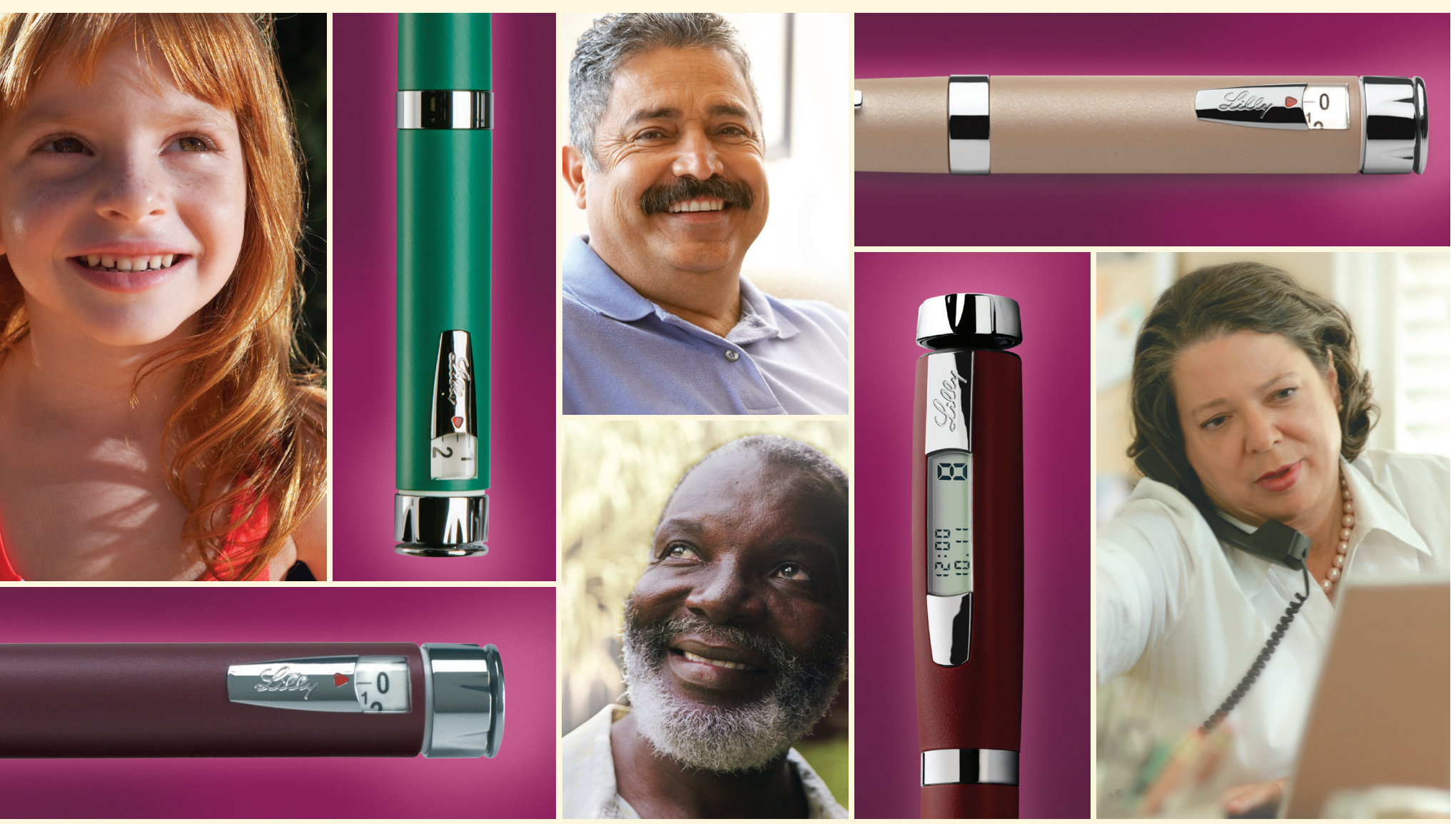

\section{Your patient's individual journey with diabetes has inspired us to create unique solutions.}

At Lilly, we realize that every person living with diabetes is on a unique journey. Your patients not only face individual challenges, they require individual solutions. That's why we're committed to offering a broad range of support. Insulin pens are one way we provide a selection of options that fit unique patient needs. For more information, please contact your local Lilly Sales Representative or the Customer Response Centre at 1-888-545-5972 (Monday to Friday 8 a.m.-5 p.m. EST).

Your journey inspires ours.

www.lilly.ca 


\section{If this is your diagnosis, you've only done half your job.}

Domestic Violence (DV) is one of the leading causes of serious injury among women. In fact, seven percent of women in Canada have been assaulted by their partners in the last five years. That makes DV more common than car accidents, diabetes, and stroke.

Some of these women will die. Often, their only intervention comes from the medical system. Emergency physicians and nurses, family health teams, nurses, gynaecologists and obstetricians all are first contacts for abused women. But in order to make a difference, we need to know what to do, what to say and how to help.

Fortunately, helping patients who have been abused is not a hard thing to do. And it's not timeconsuming. But it does take some education.

You can learn more about domestic violence and earn valuable CME credits from the Royal College of Physicians and Surgeons of Canada, the College of Family Physicians of Canada, and the Emergency Nurses Association of Ontario at the same time. Visit us on-line at www.DVeducation.ca 